Sādhanā Vol. 38, Part 1, February 2013, pp. 69-88. (C) Indian Academy of Sciences

\title{
Strengthening of non-seismically detailed reinforced concrete beam-column joints using SIFCON blocks
}

\author{
I S MISIR* and S KAHRAMAN \\ Civil Engineering Department, Faculty of Engineering, Dokuz Eylul University, \\ Buca 35160, Izmir, Turkey \\ e-mail: serkan.misir@deu.edu.tr
}

MS received 1 April 2012; revised 4 October 2012; accepted 14 October 2012

\begin{abstract}
This article aims to propose a novel seismic strengthening technique for non-seismically detailed beam-column joints of existing reinforced concrete buildings, typical of the pre-1975 construction practice in Turkey. The technique is based on mounting pre-fabricated SIFCON composite corner and plate blocks on joints with anchorage rods. For the experimental part three $2 / 3$ scale exterior beam-column joint specimens were tested under quasi-static cyclic loading. One of them was a control specimen with non-seismic details, and the remaining two with the same design properties were strengthened with composite blocks with different thickness and anchorage details. Results showed that the control specimen showed brittle shear failure at low drift levels, whereas in the strengthened specimens, plastic hinge formation moved away from column face allowing specimens to fail in flexure. The proposed technique greatly improved lateral strength, stiffness, energy dissipation, and ductility.
\end{abstract}

Keywords. Non-seismically detailed RC beam-column joint; shear failure of joint; seismic strengthening; strengthening of joints using SIFCON blocks.

\section{Introduction}

Recent earthquakes in Turkey, such as Kocaeli and Duzce in 1999 and Van in 2011, where numerous buildings were destroyed with often fatal consequences, have drawn the attention of the public to the issue of buildings' seismic safety. Following the seismic assessment of buildings in Istanbul and other densely populated regions where earthquakes are an anticipated threat, it was revealed that the existing reinforced concrete buildings have many inadequacies (Erdik 2001). Among those inadequacies, past earthquakes have demonstrated that beam-column joints and especially exterior joints of reinforced concrete frames are of critical importance to the building's resistance during an earthquake. Indeed, many structures collapsed or were heavily damaged

*For correspondence 
due to brittle joint shear failure before the plastic hinge formation at the ends of beam and column elements. Numerous buildings constructed prior to 1975 have non-ductile reinforcement detailing due to the earthquake design regulations of that time (Hakuto et al 2000; Engindeniz et al 2005). Many buildings constructed in the following years were also built without sufficient seismic considerations and do not meet the capacity design principles due to the lack of shear reinforcement in the joints. Furthermore, there is a possibility that the methods applied in the retrofitting of column and beam elements may make the joints a weak link during the force transfer between these elements (Misir 2011).

The most frequent failure mode of beam-column joints is the joint shear failure and the impaired adherence of longitudinal reinforcements anchored to the joint (Park \& Paulay 1975). Remarkable studies have been conducted on seismic rehabilitation techniques over the last twenty years in an attempt to reduce the seismic risk of existing buildings. Numerous methods have been proposed about retrofitting/strengthening of beam-column joints. Wrapping of joints with reinforced concrete jacketing has been the most studied technique (Alcocer \& Jirsa 1993). However, this method causes the jacket to run over floorings and thus has architecturally limited area of use. Enhancing the shear strength of joints through the use of steel plates, rods and jacketing have been studied as well (Beres et al 1992; Ghobarah et al 1996). Steel jacketing has produced successful results in the enhancement of the shear strength of joints. However, additional materials installed for fire protection and the corrosion risk complicates the widespread utilization of this technique.

Many studies are also conducted on the enhancement of the shear strength of joints through the use of Fibre Reinforced Polymer (FRP) composites (Gergely et al 2000; Ghobarah \& El-Amoury 2005; Akguzel \& Pampanin 2012; Parvin et al 2010; Ilki et al 2011). In this method, glass or carbon based materials (GFRP or CFRP) are adhered to the joint interface by the use of epoxy resin. FRP composites have the advantages of fast and easy application, high strengthto-weight ratio and resistance to corrosion. This method ensures high levels of strength and ductility. Its high cost, vulnerability to fire and the difficulties in applying it to the interior and exterior joints of real buildings as studies are generally conducted on plane joint specimens restricts this method's area of use as well.

Another method elaborates on the enhancement of the shear strength of joints by epoxy anchors installed in two diagonal directions (Gokdemir 2008). Furthermore, there are studies on the reduction of joint stresses by metallic belts installed diagonally between beam and column elements (Pampanin et al 2006). Thus, the function of joints to transmit the load between beam and column elements is diminished.

The method known as the planar joint expansion recommends expanding the shear area of the joint through the use of on-site cast reinforced concrete (Pimanmas \& Chaimahawan 2010). It is emphasized that this method is a low-cost option compared to other methods due to the use of conventional materials and ease of implementation. On the other hand, this method requires the application of chemical anchorage; moreover, applying the on-site cast concrete below the beam presents application difficulties.

The present study proposes a novel seismic strengthening technique for non-seismically detailed beam-column joints of existing reinforced concrete frame buildings. The method uses pre-fabricated blocks of SIFCON (figure 1), a new generation composite type which can be described as a special type of steel fibre-reinforced cement composite with fibre volume fraction values between 5 and 30\%. SIFCON has superior mechanical properties such as compressive, tensile, shear, and flexural strengths with extraordinary toughness (Yazici et al 2010). Its high mechanical strength and energy dissipation capabilities make it especially efficient when used to make structures seismically resistant (Homrich \& Naaman 1987; Wood 2000; Dogan \& 


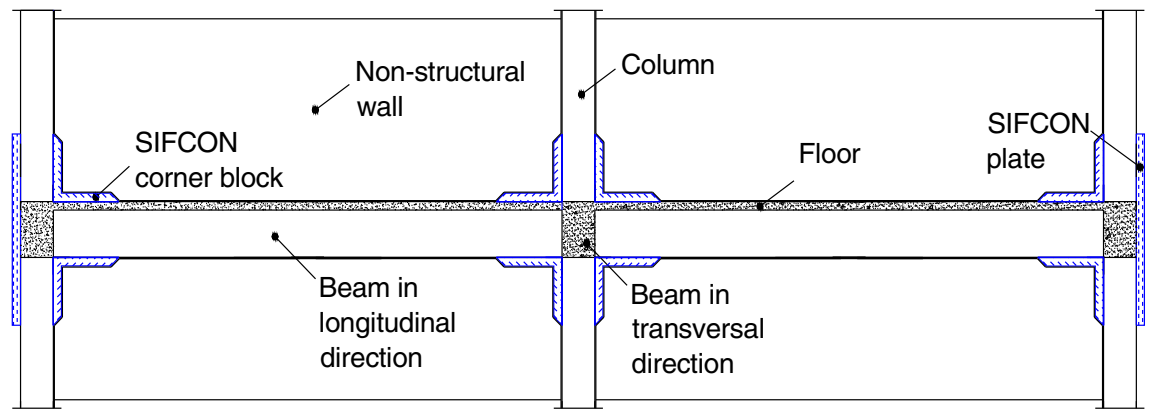

Figure 1. Strengthening of a reinforced concrete frame structure with pre-fabricated composite blocks.

Krstulovic-Opara 2003; Wu et al 2010). In the proposed method, composite corner and plate blocks placed in the plane of frame elements are anchored to column and beam elements. Blocks can be applied to the frames in each direction independently from each other. Implementation of the method is relatively easy and the pre-fabricated manufacture of the blocks is a cost-reducing factor. Moreover, as the composite blocks can be concealed into masonry walls, the method does not cause any run-over onto the floorings unlike the concrete jacketing method.

However, like other strengthening/retrofitting methods, this one also has its own restrictions. Column and beam elements may be exposed to higher shear forces due to their reduced lengths and increased stiffness of the elements. This method can be implemented in cases where the shear capacity of the joint and the anchorage length of the beams at the beam-joint interface are inadequate. In case of inadequate lateral stiffness problem such as soft story irregularity, other methods can be more appropriate, such as the addition of a reinforced concrete shear walls or seismic retrofit of infill walls (Canbay et al 2003; Binici et al 2007; Ozden et al 2011).

Considering the zero-moment points approximately in the middle of the elements as seen in figure $2 \mathrm{a}$, bending moments of frame elements under lateral earthquake forces exhibit a linear change between the nodal points (particularly for column elements). As demonstrated in figure $2 \mathrm{~b}$, the largest moments with different signs are on the borders of the joint. Moments change sign from one joint interface to another along the joint panel. Slope of the moment diagram along the height of the joint corresponds to the shear force of the joint. Thus, the shear force influencing the joint is several times greater than the shear force of the neighbouring elements.

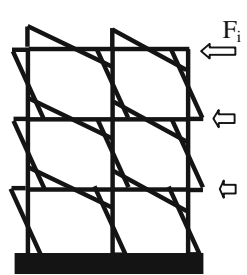

(a)

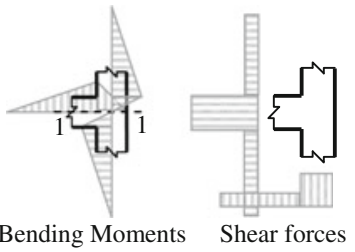

(b)

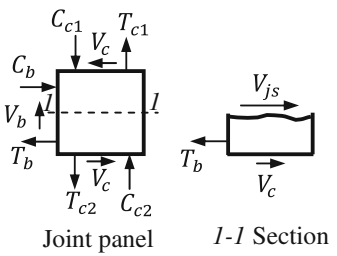

(c)

Figure 2. (a) Bending moments of frame elements under equivalent lateral earthquake forces. (b) Moment and shear forces developed in an exterior joint. (c) Internal forces acting on joint panel and resultant joint shear force. 
As seen in figure 2c, due to the internal forces transmitted to the exterior beam- column joint, horizontal joint shear force $\left(V_{j s}\right)$ is calculated with the following equation:

$$
\mathrm{V}_{j s}=\mathrm{T}_{b}-\mathrm{V}_{c}
$$

Here, $\mathrm{T}_{b}$ is the resultant tensile force in beam at the beam-joint interface and $\mathrm{V}_{c}$ is the column shear force.

Main objectives of the implemented strengthening method are;

(i) Increasing the shear capacity of non-seismically detailed beam-column joint by increasing the effective shear area to prevent, delay or restrict the potential joint shear failure (Pimanmas \& Chaimahawan 2010),

(ii) Enhancing the energy dissipation performance of the damaged joint by maintaining the integrity of the joint,

(iii) Increasing the bond length of beam longitudinal reinforcement by carrying the potential beam flexural damage away from the column face, and transform the damage mode from joint shear failure to beam flexural failure.

\section{Experimental studies}

\subsection{Test specimens}

The experimental program covers the tests on three exterior joint specimens with $2 / 3$ geometric scale, namely; S1, S2 and S3. The tests were conducted in the Structural Mechanics and Earthquake Engineering Laboratory of DEU. S1 specimen is un-strengthened control specimen. The other two specimens - S2 and S3 that have the same dimensions and reinforcement details as $\mathrm{S} 1$, but were strengthened with SIFCON plate and corner blocks using chemical anchorages.

As the potential implementation of the method concerns reinforcing existing buildings, test specimens were formed so that they represent an exterior beam-column joint detached from zero-moment points of a multi-storey frame building and designed in accordance with the strong column-weak beam approach. No shear reinforcement was placed onto the joint and low-strength concrete was used in an attempt to ensure that it possessed the general inadequacies of the building it represented. In addition, upper column longitudinal bars just above the floor level have inadequate bond length because of inadequate lap-splice and the use of plain reinforcement.

\subsection{Control specimen $\mathrm{S} 1$}

Dimensions and reinforcement details of the control specimen is given in figure 3. Crosssectional dimensions of beam and column elements are $200 \mathrm{~mm} \times 330 \mathrm{~mm}$ and $200 \mathrm{~mm} \times$ $200 \mathrm{~mm}$, respectively. These elements have longitudinal bars with a diameter of $8 \mathrm{~mm}$ and $10 \mathrm{~mm}$, and stirrups with a diameter of $4.5 \mathrm{~mm}$ which are plain round reinforcements. Tensile tests of these reinforcing bars used in the specimens were conducted under monotonic loading, and the average values are given in table 1 . A cylinder compression strength of $f_{c}^{\prime}=10 \mathrm{MPa}$ was intended in the specimens to represent the low concrete quality generally observed in old type structures. Average cylindrical compression strengths of the concrete reached on the test day of each joint specimen are given in table 2 . The specimens were cast at a pre-cast concrete facility and were transported to the laboratory. Normal weight ready-mix concrete with a maximum diameter of $8 \mathrm{~mm}$ for coarse aggregate was used. Each specimen was cast in a lubricated mold located horizontally in one sitting and concrete vibrator is used during the concrete pouring. 


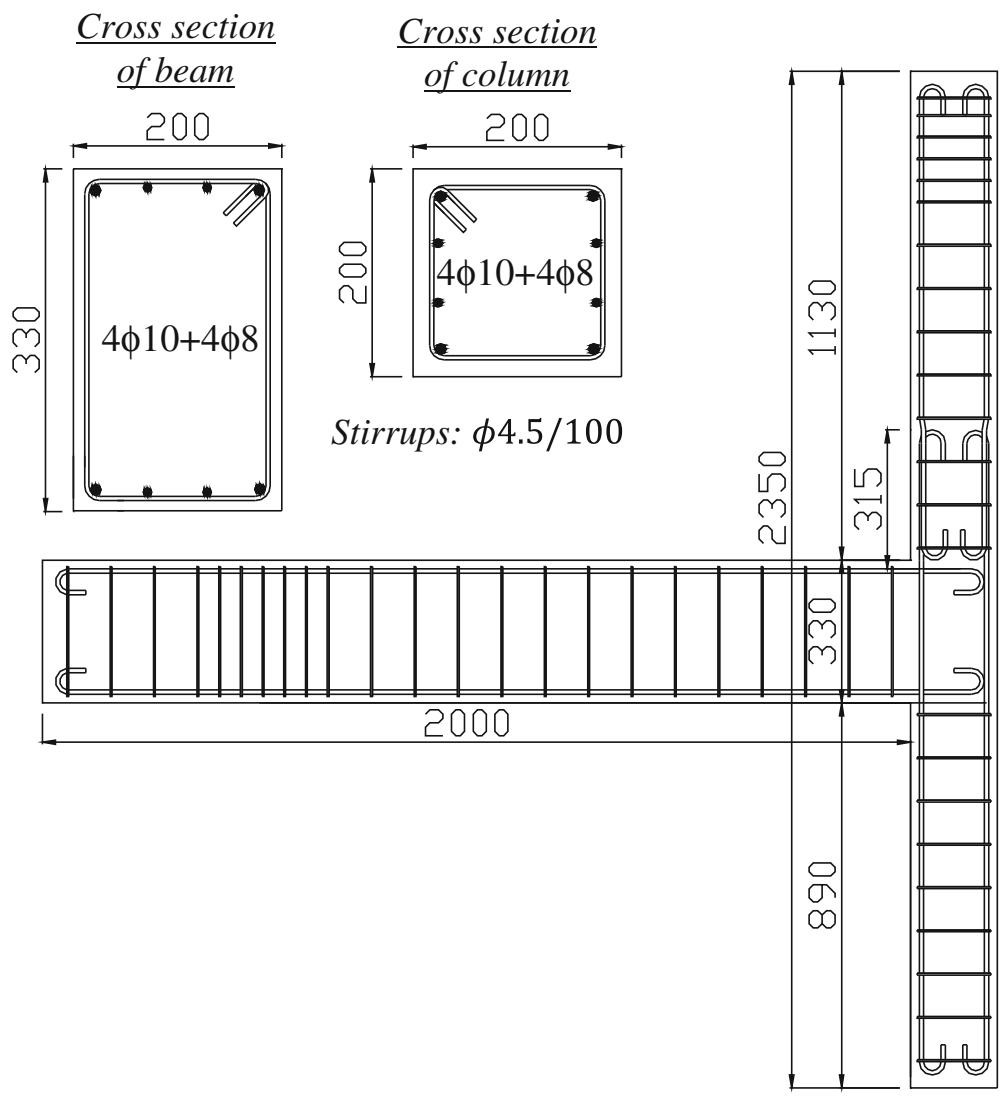

Figure 3. Dimensions $(\mathrm{mm})$ and reinforcement details of the control specimen.

Table 1. The characteristic values of the reinforcing bars.

\begin{tabular}{lcccc}
\hline Diameter & $\begin{array}{c}\text { Yield stress } \\
f_{y}[\mathrm{MPa}]\end{array}$ & $\begin{array}{c}\text { Strain at yield } \\
\text { stress, } \varepsilon_{y}[\varepsilon]\end{array}$ & $\begin{array}{c}\text { Initial elasticity } \\
\text { modulus, } E_{s}[\mathrm{MPa}]\end{array}$ & $\begin{array}{c}\text { Tensile strength } \\
f_{u}[\mathrm{MPa}]\end{array}$ \\
\hline$\phi 4.5$ & 420 & 0.0020 & 205000 & 536 \\
$\phi 8$ & 402 & 0.0020 & 201000 & 557 \\
$\phi 10$ & 411 & 0.0020 & 205600 & 528 \\
\hline
\end{tabular}

Table 2. The average compression strength of concrete.

\begin{tabular}{llcc}
\hline Specimen & $\mathrm{S} 1$ & $\mathrm{~S} 2$ & $\mathrm{~S} 3$ \\
\hline$f_{c}^{\prime}(\mathrm{MPa})$ & 9.1 & 11.0 & 11.2 \\
\hline
\end{tabular}




\subsection{Strengthened specimens $S 2$ and $S 3$}

Dimensions and reinforcement details of the strengthened specimens are the same as those of the control specimen except for the added composite blocks and anchorages. Strengthening details of S2 and S3 specimens are given in figure 4. In terms of the applicability of the strengthening work and in order to carry the anchorages sufficiently away from the column face, length of both legs of the corner blocks were taken as $400 \mathrm{~mm}$. Dimensions of composite blocks that are perpendicular to the plane of paper are the same as the dimension of the column and beam element, which is $200 \mathrm{~mm}$. Material tests and casting of the composite blocks used for strengthening purposes were carried out in the Structural Materials Laboratory of Dokuz Eylul University. Also

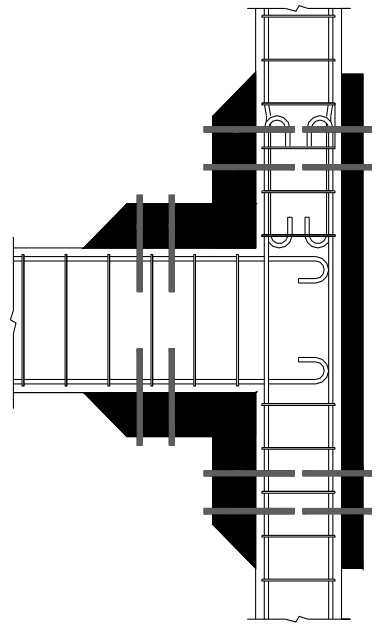

(a)

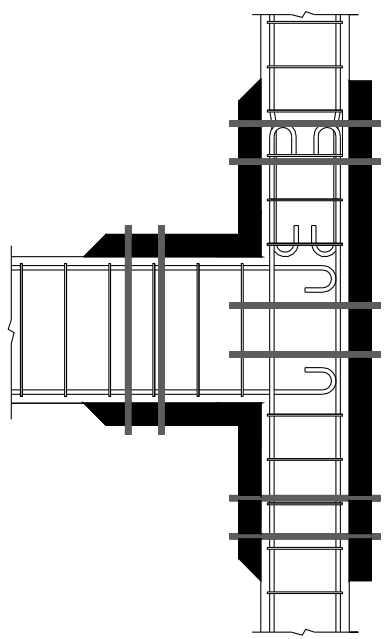

(c)

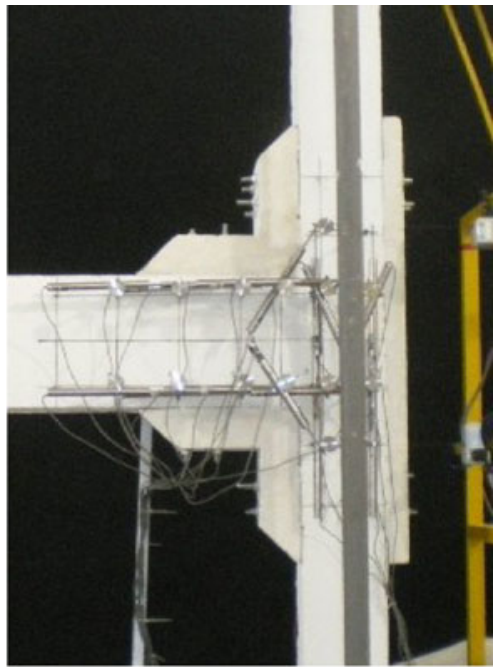

(b)

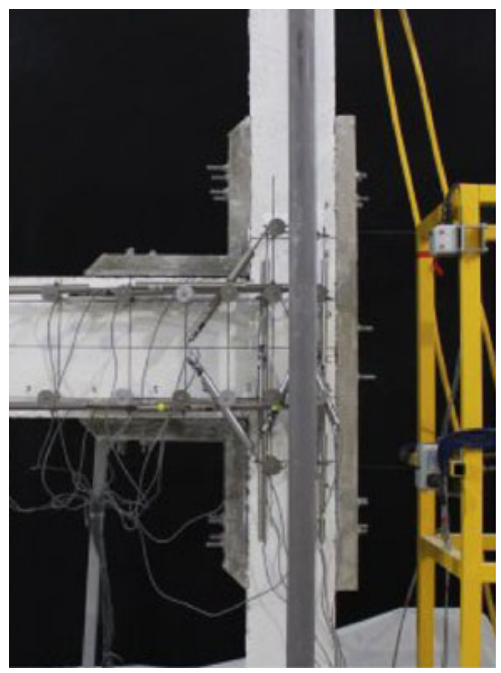

(d)

Figure 4. The strengthening details of S2 specimen in (a) and (b), S3 specimen in (c) and (d). 
preliminary cyclic tests have been conducted on composite corner blocks. The test variables were compressive strength of composite matrix, volumetric ratio of fibres, thickness of composite block and the anchorage length and orientation of the rods. The test programme was designed to investigate the effects of these parameters on the stiffness and strength degradation and energy dissipation performances of composite blocks. Because of the non-ductile nature of anchorage failure, length and orientation of the rods were selected as to prevent this behaviour (Misir 2011).

S2, the first strengthened specimen, was prepared to prevent or at least delay the joint shear damage observed during the test of control specimen S1 and change the failure mode from brittle joint shear failure into flexural failure in beam. For that purpose, relatively stiff blocks that would keep the joint integrity as far as possible were placed and anchored to the joint of S2 specimen as demonstrated in figure 4a. Strengthening was applied in S2 specimen through the use of SIFCON composite blocks that contain $10 \%$ steel fibre volumetrically and have a matrix compressive strength of $50 \mathrm{MPa}$. Dramix RC-80/60-BN, hooked-end steel fibres were used in the composites. Fibres are $60 \mathrm{~mm}$ long with the diameter of $0.75 \mathrm{~mm}$ and the nominal tensile strength is $1050 \mathrm{MPa}$. Thicknesses of SIFCON plate and corner blocks were $50 \mathrm{~mm}$ and $100 \mathrm{~mm}$, respectively. In order to fix the composites, $4 \phi 12$ anchorage rods with $490 \mathrm{MPa}$ tensile strength were placed into $100 \mathrm{~mm}$ depth at each anchorage area with epoxy-based chemical adhesive (Sika AnchorFix-3), and nuts on the rods were screwed at $40 \mathrm{Nm}$ torque after the curing as explained in the manufacturer's instructions.

S3 specimen was strengthened with composites that have the same fibre volume and matrix compressive strength as those used in S2. However, unlike in S2 specimen, corner blocks had a thickness of $50 \mathrm{~mm}$ and anchorage rods were extended along the sections of the beam and column elements (figure 4b). Furthermore, two new anchorage rods were installed to a depth of $250 \mathrm{~mm}$ from the composite plate block into the joint. Thus, the joint was reinforced inside and the free length of the composite plate block was also reduced.

\subsection{Test set-up, loading and instrumentation}

Joint specimens were tested on the strong frame shown in figure 5a based on ACI 374.1-05 (ACI Committee 374 2005) and were observed through the instrumentation shown in figure 5b. Specimens were mounted in accordance with the position of the represented exterior beamcolumn joint inside the building so that the beam element is horizontal and column elements stand vertical. In order to simulate the gravity load on columns, column-enclosing frame was used and a load was applied onto the column at $15 \%$ of the columns' axial load capacity. Quasistatic cyclic loading was applied at the top of the specimens in horizontal direction by the use of a hydraulic actuator with $500 \mathrm{kN}$ capacity. The pendulum uniting the beam end with strong steel frame allows displacements in the direction of the applied horizontal load and ensures that the beam end performs a displacement similar to that of the joint vertically (figure 6a).

Lower end of the column was attached to the steel frame with a single-axis fixed support, and potential uncontrolled displacements of the column base were limited by fixing elements installed to the base plate. Interstory drift ratio $(\delta / \mathrm{L})$ is obtained by dividing the horizontal displacement of the column top of the specimen $(\delta)$ by the clear column height $(\mathrm{L}=2330 \mathrm{~mm})$. Loading steps were performed at predefined drift ratios starting with $0.15,0.25,0.35,0.50 \% \ldots$, shown in figure $6 \mathrm{~b}$. Three cycles were applied for each drift ratio in order to observe the reduction in the strength and stiffness of the specimens in repeated cycles. The applied loading was continued up to a drift level of at least $3.5 \%$ in an effort to observe the post-elastic behaviour.

Lateral load applied to the column top and shear force in beam were measured during the tests by loadcells embedded on the actuator and pendulum. Strains of longitudinal reinforcement 


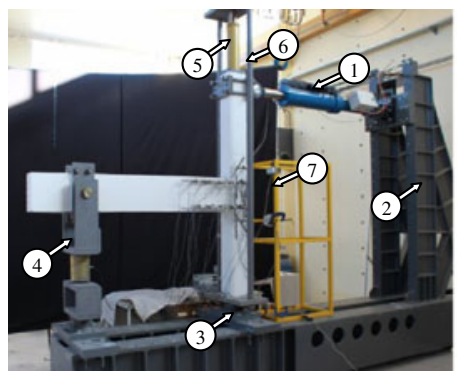

(a)

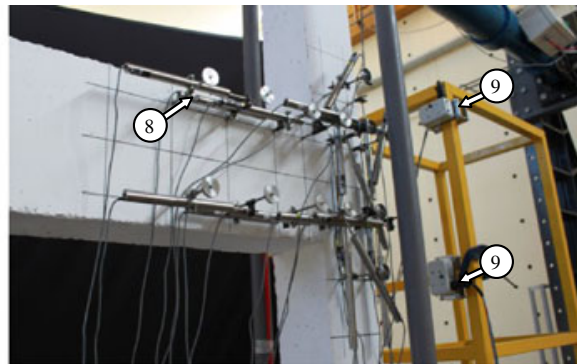

(b)

Figure 5. (a) General view of test set-up: (1) actuator, (2) reaction frame, (3) single-axis fixed support, (4) pendulum, (5) hydraulic ram and, (6) steel frame for axial loading of column, (7) reference frame. (b) Locations of displacement transducers: (8) LVDT's, (9) string potentiometers.

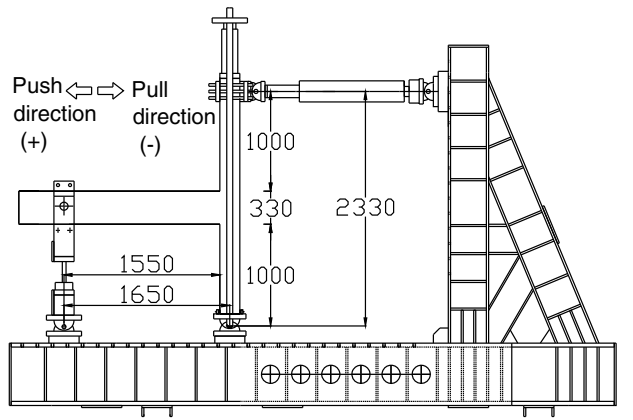

(a)

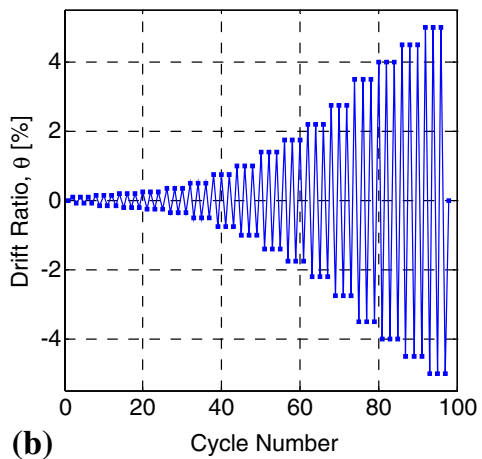

(b)

Figure 6. (a) Location of specimen in the test set-up, (b) applied displacement cycles.

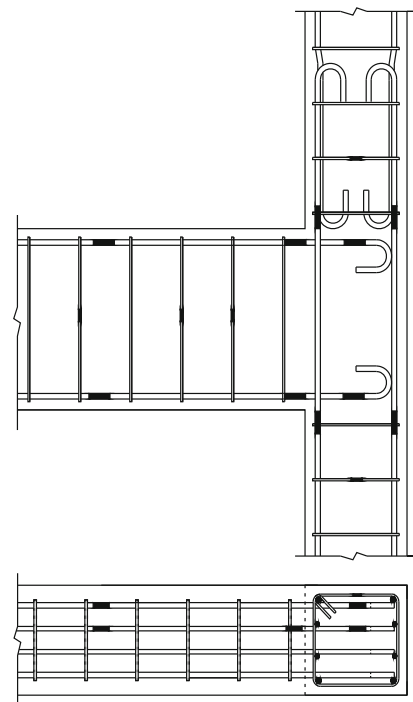

(a)

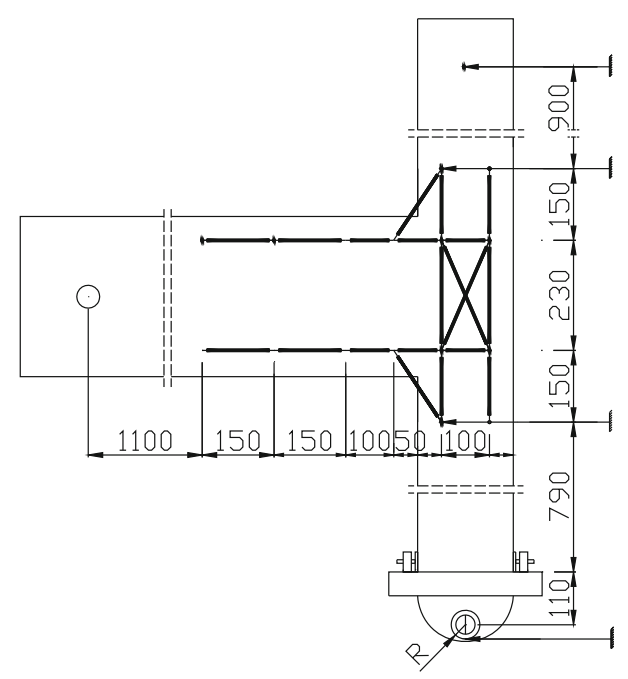

(b)

Figure 7. Sensor layout; (a) strain gauge, (b) displacement transducer. 
(a) S1

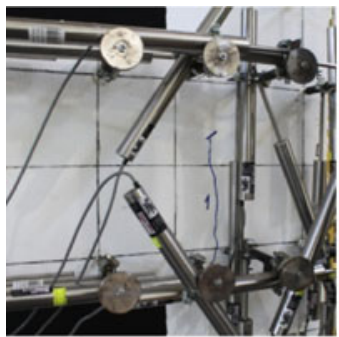

$\pm \% 0.15$

(b) $\mathrm{S} 2$

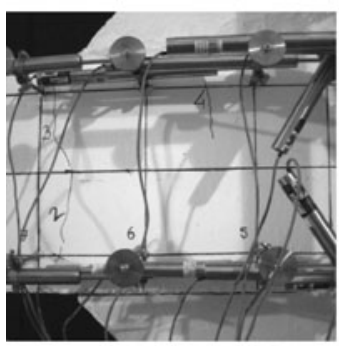

$\pm \% 0.15$

(c) S3

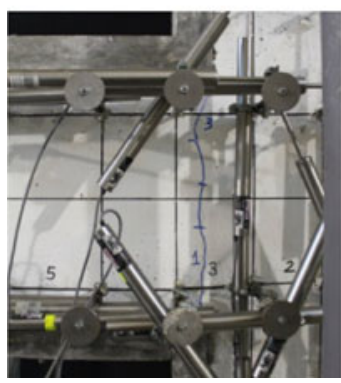

$\pm \% 0.15$

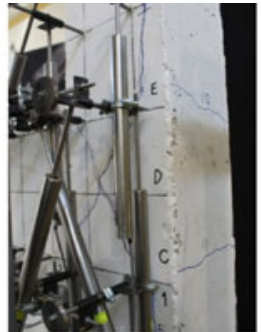

$\pm \% 1.0$

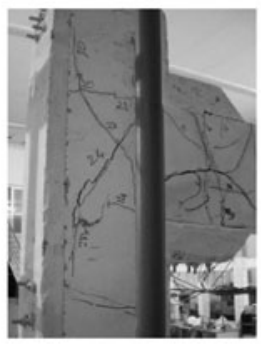

$\pm \% 2.75$

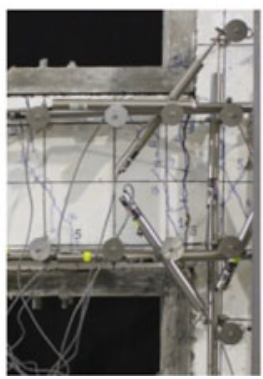

$\pm \% 2.75$

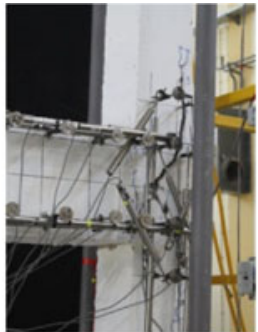

$\pm \% 1.75$

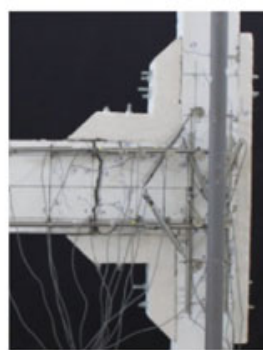

$\pm \% 3.5$

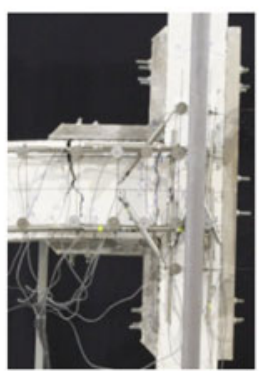

$\pm \% 3.5$

Figure 8. Crack observations of; (a) S1, (b) S2, and (c) S3 specimens.

and stirrups were monitored with 19 strain gauges located at critical sections given in figure 7a. Deformations of the specimens were monitored by totally 20 LVDTs placed in the configuration demonstrated in figure $7 \mathrm{~b}$. Moreover, deformations of the lower support of the column, lower and upper level of the beam and column top with respect to the reference frame were observed using 4 string potentiometers. The data was recorded with $125 \mathrm{~ms}$ intervals using TDG Ai8b data acquisition system operating at 16 bit data resolution and TDG Testlab Basic software.

\section{Experimental results}

General behaviour and failure mechanisms of the test specimens were assessed using the resulting crack patterns and top load-drift ratio responses. Observed cracks on each specimen during the test are given in figure 8 and load-drift ratio hysteretic curves are given in figure 9. 

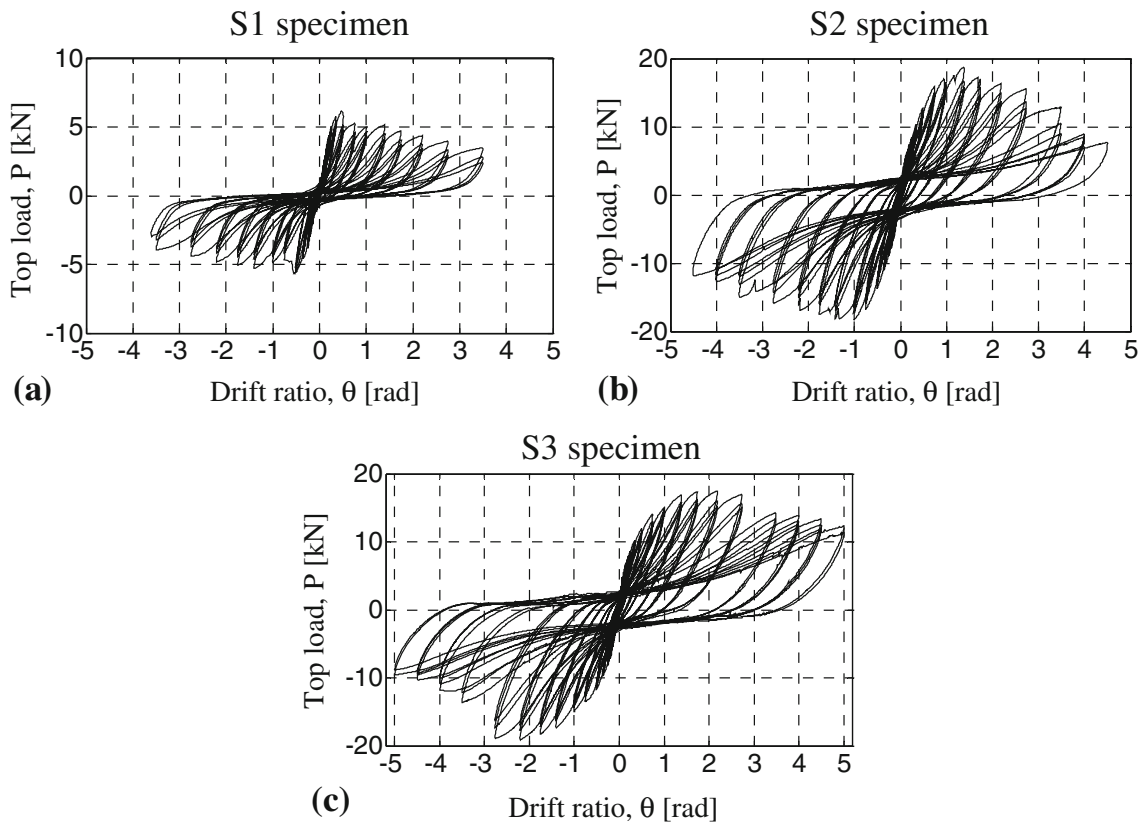

Figure 9. Top load-drift ratio hysteretic response of the specimens.

\subsection{Control specimen S1}

Cracking patterns of S1 control specimen are given in figure 8a. The first flexural cracks on the beam-joint interface were observed at $\pm 0.15 \%$ drift ratio, and these cracks converged as the drift ratio increased. The first diagonal cracks on the joint were observed at $+0.5 \%$ and $-0.75 \%$ drift ratios. At this level of drift, the number of shear cracks increased, their width expanded, but no new cracks developed on the beam and the existing cracks lost their effectiveness. At $\pm 1.0 \%$, joint cracks followed the column longitudinal bars and extended towards inside the columns. At $\pm 1.4 \%$, a concrete cone occurred, shaping outwards from the free surface of the joint, whereas above the drift ratio of $\pm 1.75 \%$, the concrete cone was detached completely, column longitudinal bars were buckled and the vertical load-bearing capacity was significantly impaired. Loading was continued up to the drift ratio of $\pm 3.5 \%$ in the heavily damaged specimen.

As seen in figure 9a, top load-drift ratio response of the $\mathrm{S} 1$ control specimen demonstrated elastic behaviour up to a drift ratio of $\pm 0.35 \%$. With $\pm 0.75 \%$ drift ratio level, pinching observed on hysteretic curves points out that the energy dissipation of the specimen decreased. Following the joint damage on both diagonal directions, top load of the specimen decreased rapidly. Thus, the peak lateral resistance observed is $6.2 \mathrm{kN}$, which occurred at $0.5 \%$ drift ratio. Top load fell abruptly due to the brittle shear failure of the joint. In the next cycles, both strength and lateral stiffness decreased continuously. In consequence, the specimen did not exhibit a good energy dissipation performance due to the strength degradation and pinching.

\subsection{S2 Specimen}

Cracking patterns of S2 specimen are given in figure $8 \mathrm{~b}$. The first flexural cracks were observed on the beam at approximately $400 \mathrm{~mm}$ distance from the column face (the end of strengthened 
region) at $\pm 0.15 \%$ drift ratio, and these cracks converged in the following cycles. Up to $\pm 1.4 \%$ drift ratio, the cracks became more intense on the beam sections where the anchorages were located (the region between $200 \mathrm{~mm}$ and $400 \mathrm{~mm}$ from the column face). The first diagonal cracks appeared on the joint at $+1.4 \%$ and $-1.75 \%$ drift ratios. The damage in the joint remained in the shape of hairline diagonal cracks up to $2.2 \%$ drift ratio and grew up to approximately $2 \mathrm{~mm}$ level when the outer anchorage in beam of the upper corner block failed in the repeating cycles. However, with the support of the plate block installed for strengthening purposes, formation of the concrete cone at the joint was prevented and the integrity of the joint was maintained. From this level of drift, the crack width on the section where the anchorages were located on the beam began to increase and at $\pm 2.75 \%$ drift level, the concrete cover began to spall off at this section. No damage was observed on the anchored composite blocks during the test, and the beam flexural failure was identified as the failure mode of the specimen. Loading was continued up to $\pm 4.5 \%$ drift level.

As seen in figure 9b, top load-drift ratio response of S2 specimen demonstrated elastic behaviour up to $\pm 0.5 \%$ drift ratios. Initial and secant stiffness's at $\pm 0.5 \%$ drift ratios of this specimen are $150 \%$ and thus $115 \%$ higher than the control specimen, respectively. At the peak lateral resistance of approximately $17 \mathrm{kN}$ reached at $\pm 1.0 \%$ drift level, beam longitudinal reinforcements reached the yield strain in the region where the strengthening ended. The peak lateral load resisted by the specimen is $18.7 \mathrm{kN}$ which corresponds to $\pm 1.4 \%$ drift ratio. Hysteretic curves of S2 specimen is prominently well-rounded compared to the control specimen.

\subsection{S3 Specimen}

Cracking patterns of $\mathrm{S} 3$ specimen are given in figure 8c. The first flexural cracks on the beam at column face were observed at the drift ratio of $\pm 0.25 \%$. At $\pm 0.75 \%$ drift ratio, hairline shear cracks appeared on the joint when the flexural cracks on the column face reached a width of approximately $1 \mathrm{~mm}$. Hairline cracks were observed on the corner blocks at $\pm 1.4 \%$ drift level. Beam flexural cracks reached a width of approximately $3 \mathrm{~mm}$ at the drift ratio of $\pm 1.75 \%$. No significant loss of strength is observed following the occurrence of the joint damage at the $\pm 0.75 \%$ drift level, and the lateral load continued to increase up to $\pm 2.75 \%$ drift level. From this level of drift, increased damage of corner blocks was observed, and the joint damage reached up to a width of approximately $0.5 \mathrm{~mm}$, but the detachment of the concrete cone was prevented owing to the plate block and the two anchorages installed in the joint, thereby maintaining the integrity of the joint. As from the drift level of $\pm 3.5 \%$, intense damage was observed on the corner blocks and anchorage areas, and widespread flexural cracks were observed on the beam. No change was noted on the axial load of the column, and the beam flexural failure was identified as the failure mode of S3 specimen. Hysteretic cycles were continued up to $\pm 5.0 \%$ drift level.

As seen in figure 9c, top load-drift ratio response of S3 specimen demonstrated elastic behaviour up to the drift ratios of $\pm 0.5 \%$. Initial and secant stiffness's at the drift level of $\pm 0.5 \%$ of this specimen are $140 \%$ and $100 \%$ higher than the control specimen, respectively. At the peak lateral resistance of approximately $18 \mathrm{kN}$ reached at $\pm 1.75 \%$ cycle, beam longitudinal reinforcements reached the yield strain in the region where the strengthening ended. The peak lateral load resisted by the specimen is $19.1 \mathrm{kN}$ which corresponds to $\pm 2.2 \%$ drift level. Hysteretic curves of S3 specimen is prominently well-rounded compared to the control specimen and exhibited a more successful energy dissipation performance in comparison to the control specimen as well as $\mathrm{S} 2$ specimen. 


\section{Evaluation of the experimental results}

The test results were assessed in terms of top load-drift ratio response, shear strain-shear stress response of joint, and contribution of the sub-assemblages' deformations to top drift. Furthermore, the changes in the lateral stiffness of the specimens as well as relative energy dissipation ratios were reviewed in comparison to each other.

\subsection{Top load-Drift ratio response}

Envelope curves of hysteretic top load-drift ratio of control and strengthened specimens, obtained experimentally are given in figure 10. Envelope curves were drawn using the peak lateral resistances obtained at each level of drift and the corresponding drift ratios. The impact of the strengthening options on the curves can be seen clearly. The peak lateral resistances reached in S2 and S3 specimens are similar. When all the curves are examined, it is seen that the drift level corresponding to peak lateral load is increased in the strengthened specimens and reached its maximum value in $\mathrm{S} 3$ specimen.

Composite blocks used to strengthen $\mathrm{S} 2$ specimen did not have any damage during the test, but the $100 \mathrm{~mm}$ deep anchorage of the upper corner block in the beam failed at $2.2 \%$ drift ratio. The first diagonal cracks in joint panel at $-1.0 \%$ and $+1.4 \%$ drift ratios limited the lateral resistance of specimen. On the other hand, a $200 \%$ higher peak lateral resistance was reached at further drifts in $\mathrm{S} 2$ specimen compared to $\mathrm{S} 1$ control specimen.

Despite the hairline joint shear cracks occurring on S3 specimen at the drift ratio of $0.75 \%$, the hairline cracks occurring on corner blocks at the drift ratio of $1.4 \%$ and the expanding beam flexural cracks, lateral load continued to increase up to the drift level of $2.2 \%$. Joint damage became intense at the drift level of $2.75 \%$, but the abrupt drop of peak lateral resistance was prevented owing to the strengthening. A $184 \%$ higher peak lateral resistance was reached in S3 specimen compared to control specimen $\mathrm{S} 1$.

As a consequence, the peak lateral top loads reached in the strengthened specimens increased considerably, the joint shear damage occurred at higher drift levels in comparison to the control specimen, and a more ductile behaviour was obtained.

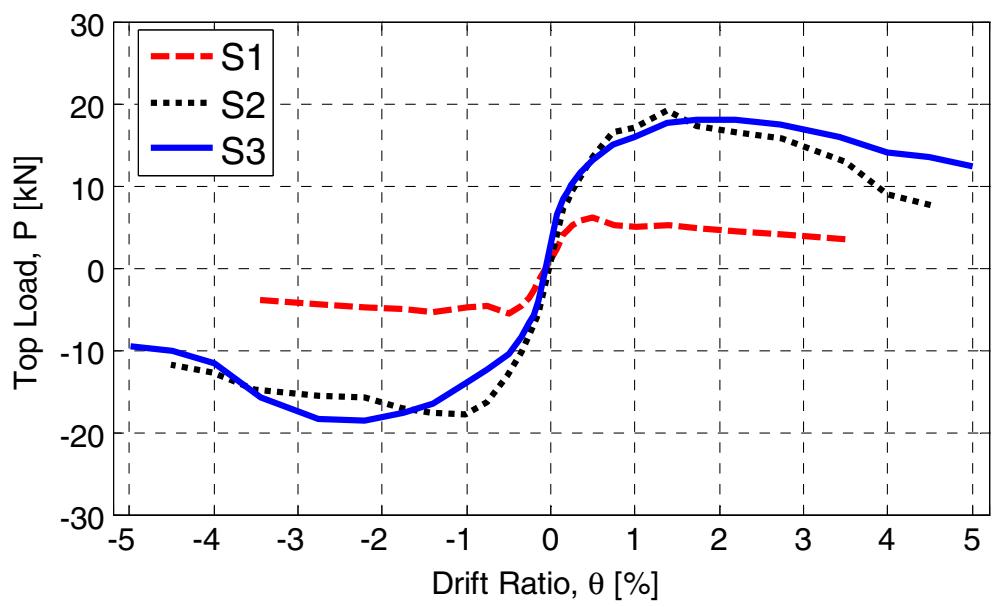

Figure 10. Envelope curves of top load—drift ratio hysteretic response of the specimens. 


\subsection{Joint Shear strain-Normalized joint shear stress}

Through the use of the data obtained from the six displacement transducers attached on joint panel shown in figure $7 \mathrm{~b}$ and the plane strain transformations, the shear strain of the joint (shear angle) was computed with the following equation:

$$
\gamma_{x z}=\frac{\varepsilon_{\varphi}-\varepsilon_{x} \cos _{\varphi}^{2}-\varepsilon_{z} \sin _{\varphi}^{2}}{\sin \varphi \cos \varphi}
$$

where $\gamma_{x z}$ is the shear strain of the joint panel, $\varepsilon_{x}$ and $\varepsilon_{z}$ are the longitudinal strains on $\mathrm{x}$ (horizontal) and $\mathrm{z}$ (vertical) directions, respectively and $\varepsilon_{\varphi}$ is the strain in joint panel in an arbitrary direction with an angle of $\varphi$ measured counterclock-wise from the horizontal axis. Shear strain was found taking the average of the values obtained in the triangular strain rosettes formed by six LVDTs placed onto the joint panel. Normalized horizontal shear stress values of the joint $\left(\tau_{j s}^{\prime}\right)$ was obtained using the equation below:

$$
\tau_{j s}^{\prime}=\frac{V_{j s}}{\sqrt{f_{c}^{\prime}} b_{j} h_{c}},
$$

where $b_{j}$ is the effective width of the joint, $h_{c}$ is the column depth, $f_{c}^{\prime}$ is the compression strength of the concrete and $V_{j s}$ is the shear force transmitted to the joint defined in ACI 352R-02 (ACI Committee 352 2002).

In the computation of $V_{j s}$ value, two different methods were employed to estimate the total normal force $\left(T_{b}\right)$ in Eq. 1 transferred to the joint on the tension side of the beam section as seen in figure 2. The moment generated by the beam shear force measured during the tests on the column face $\left(M_{z}\right)$ is used in the first method. Under the assumption that the moment arm between the tensile and compression resultant forces that will develop on the beam section will remain constant $(j d=0.875 d)$ (Engindeniz 2008), $T_{b}$ is calculated as $T_{b}=M_{z} /(0.875 d)$. In the second method, $T_{b}$ force is computed as the resultant tensile force in beam at the column face, using the data taken from strain gages placed on the beam longitudinal bar. In the transformation of strain values to forces, nonlinear analysis was conducted with the steel characteristic values of the relevant reinforcement and appropriate reinforcement modelling in OpenSees software (McKenna 2011).

$\tau_{j s}^{\prime}$ values computed for strengthened specimens as explained above and the corresponding joint shear strain values are plotted and compared to those of the control specimen are given in figure 11. $\tau_{j s}^{\prime}$ values computed through the strains of beam bars are given with a round sign for the target drift values on positive and negative directions. Since a portion of the shear force in
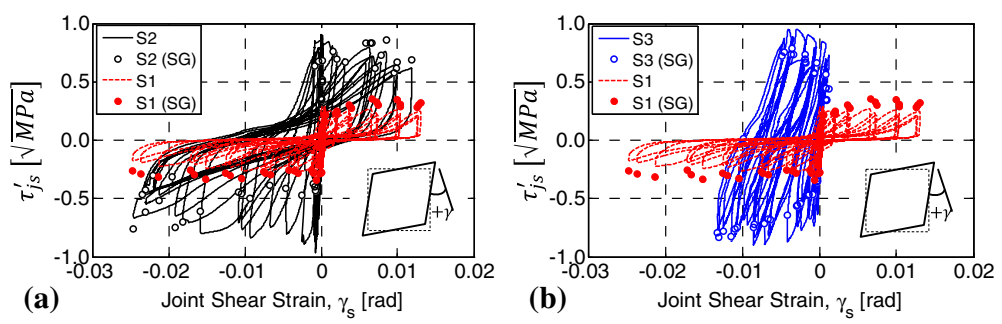

Figure 11. Joint shear strain-stress hysteresis loops; (a) S1 and S2 specimens, (b) S1 and S3 specimens. 
the strengthened specimens is transmitted by the composite blocks, strains found by these two methods somewhat differ.

Owing to the strengthening application, joint shear stress-strain behaviour was improved significantly by maintaining the integrity of the joint (figure 11). For S2 specimen, the joint distortion increased only after the outer anchorage in beam of the upper corner block failed in the repeating cycle of $2.2 \%$ drift. For S3 specimen, no significant loss of strength is observed following the occurrence of joint shear cracks at $\pm 0.75 \%$ drift level, and the top load continued to increase up to $\pm 2.75 \%$ drift level as well. The maximum normalized joint shear stresses of $0.94 \sqrt{M P a}$ and $0.96 \sqrt{M P a}$ obtained for the positive loading direction of S2 and S3 specimens respectively, are two times more than $0.29 \sqrt{M P a}$ obtained for the control specimen. These values for strengthened specimens are very close to $1.0 \sqrt{M P a}$ which is recommended by ACI 352R-02 for type-2 exterior connections in new designs, structurally similar to those presented in the current study.

\subsection{Contributions to the top drift}

Displacement transducer readings were used to determine the contributions of the subassemblages' (joint, column and beam) deformations to the top drift for each loading cycle approximately (Misir 2011) and are given in figure 12 .

As shown in figure 12a, contribution of the joint deformations increased continuously from the $10^{\text {th }}$ cycle (drift level of $0.5 \%$ ) in which the shear crack was observed for the first time in the joint of the control specimen S1, and reached approximately $75 \%$ in the $33^{\text {rd }}$ cycle (drift level of $3.5 \%$ ), thereby being a factor directing the behaviour.

Contribution of the beam in S2 specimen increased from the first flexural crack up to the anchorage distortion that occurred in the $25^{\text {th }}$ cycle (drift level of $2.2 \%$ ). The joint damage that occurred at the drift level of $1.4 \%$ remained in the shape of hairline shear cracks owing to the applied strengthening. With the joint damage observed on the negative direction in the $25^{\text {th }}$ cycle, the contribution of the joint began to increase as demonstrated in figure $12 \mathrm{~b}$. However, owing to the fact that the strengthening application maintained the integrity of the joint, contributions of the joint and the beam were found to be $29 \%$ and $71 \%$ respectively at the end of the test. As a consequence, deformations of the beam directed the behaviour.

Contribution of the beam in S3 specimen increased from the first flexural crack up to the $19^{\text {th }}$ cycle (drift level of $0.75 \%$ ) depending on the intensity of the damage (figure 12c). With the joint shear cracks that occurred at this level of drift, the contribution of the joint reached $10 \%$, and peaked in the $26^{\text {th }}$ cycle (drift level of $1.4 \%$ ), reaching $18 \%$. Due to the beam flexure, which had again an increased effectiveness as from this level, the contribution of the beam escalated until the end of the test and directed the behaviour. Contributions of the joint and the beam were $6 \%$ and $82 \%$ respectively at the end of the test.

\subsection{Stiffness degradation}

Peak-to-peak stiffness method was employed to assess the behaviour of the specimens tested under quasi-static loading in terms of the reduction of lateral stiffness. As demonstrated in figure 13a, peak-to-peak stiffness values, known as the slope of the line linking the peak points reached on positive and negative directions in a loading cycle, were computed using the following equation:

$$
K_{t, i}=\frac{E_{1, i}+E_{2, i}}{\Delta_{1, i}+\Delta_{2, i}}
$$



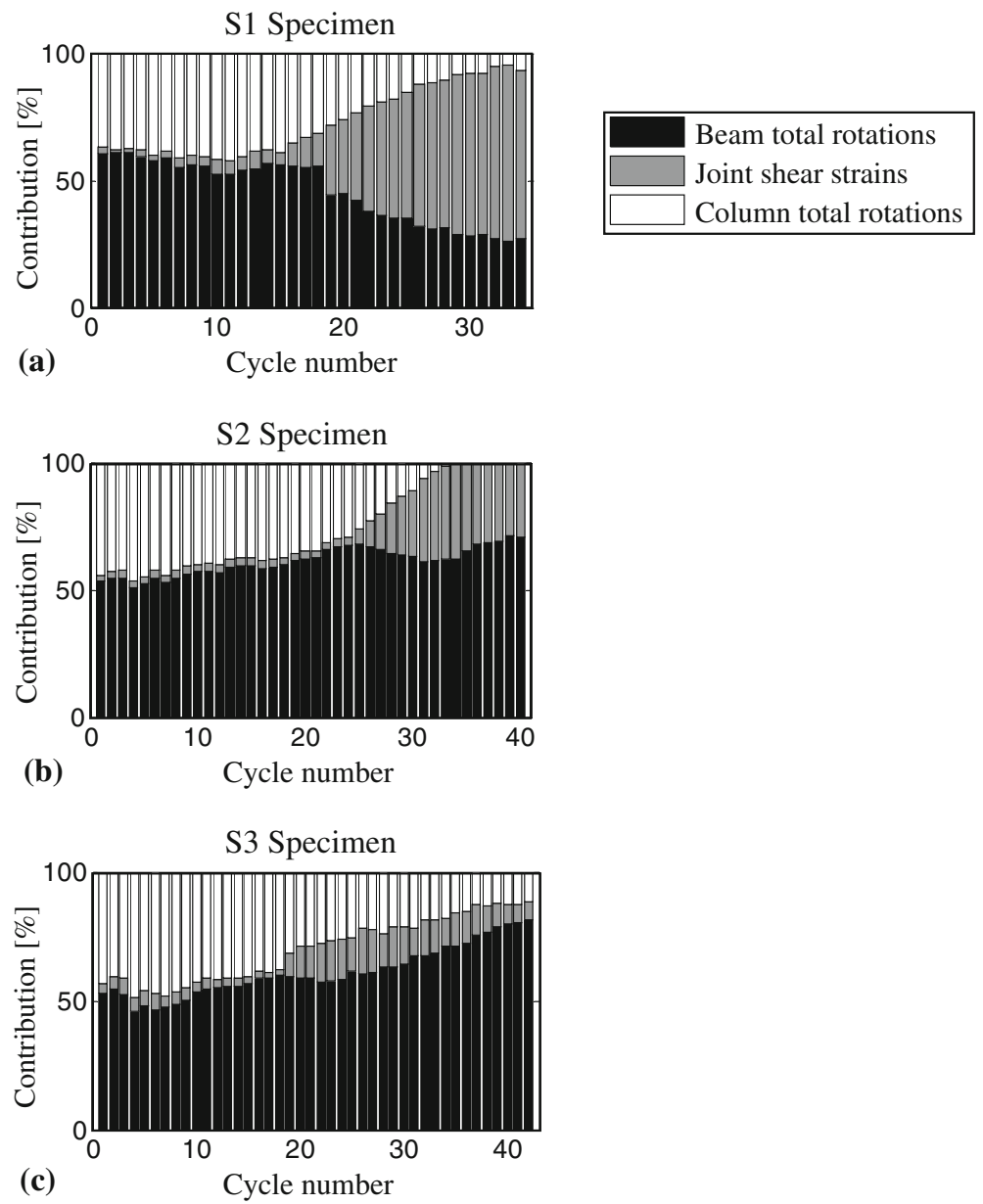

Figure 12. Contributions of sub-assemblage deformations to top drift.

where $E_{1, i}, E_{2, i}, \Delta_{1, i}$ and $\Delta_{2, i}$ values are peak lateral resistances for positive and negative loading direction for third cycle of $i^{\text {th }}$ loading sequence and the corresponding drifts, respectively. Lateral stiffness-drift ratio graphs for each specimen are given in figure 13b. As seen on the figure, control specimen S1, which did not have shear reinforcement on its joint, exhibited brittle failure, and constituted the lower limit among other curves. Adverse impact of the joint damage developing at the drift levels of $0.5 \%$ and $0.75 \%$ on lateral stiffness is significant.

Approximately 120\% increase was observed on the initial stiffness of both S2 and S3 specimens relative to $\mathrm{S} 1$ specimen. Stiffness of these specimens at the drift level of $1.75 \%$ is approximately two and a half times higher than that of S1 specimen. Initial stiffness of the specimens $\left(K_{b}\right)$ and stiffness values corresponding to the peak resistance $\left(K_{E_{m a k s}}\right)$ are given in table 3. The table also contains the reserve stiffness capacities $\left(K_{E_{m a k s}} / K_{b}\right)$ corresponding to the peak resistance. $\Delta_{E_{m a k s}}$ in the table is the drift corresponding to the peak resistance for each specimen. Points on figure $13 \mathrm{~b}$ represent the stiffness values at which the maximum load was attained for each specimen. Control specimen exhibited serious stiffness degradation when peak 


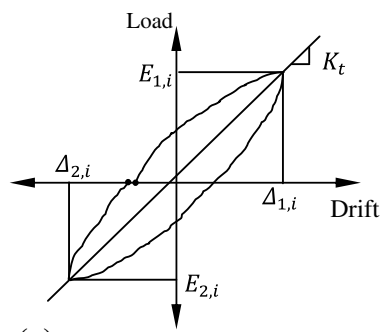

(a)

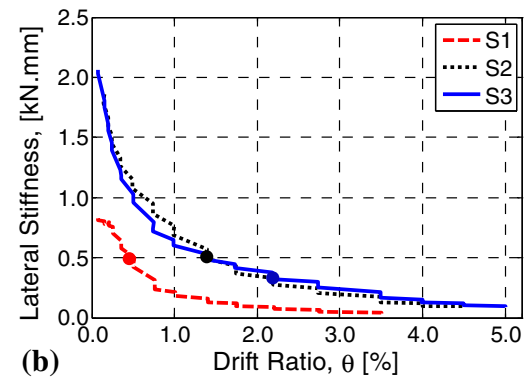

(b)

Figure 13. (a) Definition, (b) degradation of peak-to-peak stiffness.

load was reached and reserved stiffness was $52 \%$ which is a high value originated from the brittle failure of the joint.

\subsection{Relative energy dissipation ratio}

As the peak lateral load increase in sequence of cycles with increasing drifts, dissipated energy value corresponding to each drift level increases naturally. Normalization of the computed energy values is a preferred method for comparison of increasing values of different specimens. As seen in figure 14a, relative energy dissipation ratio is the proportion of the shaded area representing the dissipated energy in the relevant cycle to the parallelogram representing the ideal energy dissipation (ACI Committee 374 2005). In order to compare the energy dissipation performances of the specimens, relative energy dissipation ratios $\left(\beta_{i}\right)$ were obtained by means of the following equation:

$$
\beta_{i}=\frac{A_{h, i}}{\left(E_{1, i}+E_{2, i}\right)\left(\theta_{1, i}^{\prime}+\theta_{2, i}^{\prime}\right)},
$$

where $A_{h, i}$, is the area of the closed curve of the $i^{\text {th }}$ target drift in the third cycle, $E_{1, i}$ and $E_{2, i}$, are the peak lateral resistances for positive and negative loading direction for the third cycle of loading sequence, and $\theta_{1, i}^{\prime}$ and $\theta_{2, i}^{\prime}$ are the drift ratios for zero lateral load for unloading at stiffness's $K$ and $K^{\prime}$ from peak positive, negative, lateral resistance for third cycle of $i^{\text {th }}$ loading sequence.

$\beta_{i}$ values, which had a downward tendency while the specimen was in the elastic region still in the first loading cycles, began to rise again with the developing cracks and dissipated energy. Curves given in figure $14 \mathrm{~b}$ for the tested specimens exhibit this behaviour as well. In ACI 374.105 which suggests acceptance criteria for structural tests of moment frames, it is recommended

Table 3. Reserve stiffness capacities.

\begin{tabular}{lccccc}
\hline Specimen & $K_{b}[\mathrm{kN} / \mathrm{mm}]$ & $E_{\text {maks }}[\mathrm{kN}]$ & $\Delta_{E_{\text {maks }}}[\%]$ & $K_{E_{\text {maks }}}[\mathrm{kN} / \mathrm{mm}]$ & $\left(\frac{K_{E_{\text {maks }}}}{K_{b}}\right)[\%]$ \\
\hline S1 & 0.81 & 6.20 & 0.50 & 0.42 & 52 \\
S2 & 2.00 & 18.70 & 1.40 & 0.49 & 28 \\
S3 & 2.03 & 19.10 & 2.20 & 0.33 & 16 \\
\hline
\end{tabular}



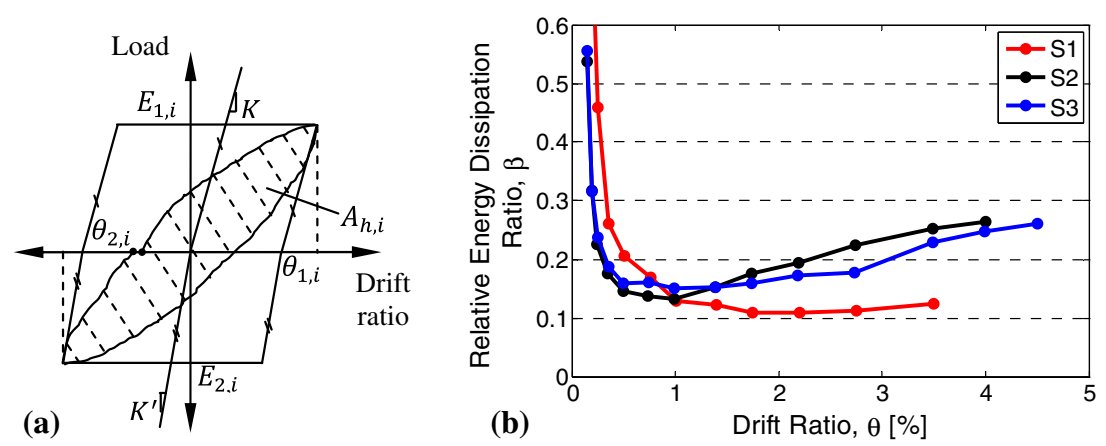

Figure 14. (a) Determination of relative energy dissipation ratio $(\beta)$, (b) relative energy dissipation ratio of the specimens.

that relative energy dissipation ratio of the tested specimens, which will be computed for the drift ratio of $3.5 \%$, is at least $12.5 \%$. The strengthened specimens reached about two times of the recommended minimum value at $3.5 \%$ drift ratio.

\section{Conclusions}

This paper proposes a novel seismic strengthening technique for non-seismically detailed beamcolumn joints of existing reinforced concrete buildings. The method uses prefabricated SIFCON composite blocks. Tests were carried out on three $2 / 3$ scaled exterior beam-column joint specimens, which represent the material properties and major deficiencies in reinforcement detailing of existing frame buildings. The following conclusions can be drawn based on the test results:

(i) Peak lateral resistance and initial stiffness values of the strengthened specimens were greatly improved in comparison to the control specimen. Stiffness of the strengthened specimens at the drift level of $1.75 \%$ are approximately two and a half times greater than that of control specimen. In addition, strengthened specimens exhibited low stiffness degradation and reserve stiffness value when peak load was attained. This indicates more ductile behaviour in contrast to the control specimen with a high reserve stiffness value due to the early and brittle failure of the joint.

(ii) Owing to the strengthening application, joint shear strains of the strengthened specimens were reduced for the same drift levels in comparison to the control specimen. Moreover, joint shear stress-strain behaviour was improved significantly by maintaining the integrity of the joint when the specimens were exposed to large drift ratios. The maximum normalized joint shear stresses obtained for strengthened specimens are very close to $1.0 \sqrt{M P a}$, the value recommended by ACI 352R-02 for new designs of type- 2 exterior connections, and are two times more than the value obtained for the control specimen.

(iii) Hysteretic curves of the strengthened specimens were prominently well-rounded and exhibited a better energy dissipation performance compared to the control specimen. The relative energy dissipation ratios obtained for strengthened specimens reached about two times the minimum value recommended by ACI 374.1-05 at 3.5\% drift ratio.

(iv) Contribution of sub-assemblages' deformations to the top drift for each loading cycle were approximated. It was observed that the failure mode of strengthened specimens was 
transformed from brittle joint shear failure to beam flexural failure. Location of the plastic hinge moved away from column face owing to the strengthening application.

(v) Because of the stiffness degradation performance and the reduced distortion of joint at higher drift levels, the strengthening scheme of S3 specimen is more effective than the strengthening scheme of the S2 specimen.

\section{Acknowledgements}

The authors are thankful to Dokuz Eylul University for providing the research fund 2008.KB.FEN.006 and to Dr. Özgür Özçelik, Sadık C. Girgin, Dr. Turkay Baran and Materials Laboratory personnel for the support to carry out this study. Authors also would like to thank Dere Precast Concrete Ind. \& Trade Co., Turkey for the support in the preparation of specimens.

\section{Symbols}
$A_{h, i}$
Area of third hysteresis loop in $\mathrm{i}^{\text {th }}$ loading sequence.
$C_{b}$ Resultant compression force at beam-joint interface.
$C_{c 1}, C_{c 2} \quad$ Resultant compression force in lower and upper column at column-joint interface, respectively.
$E_{1, i}, E_{2, i} \quad$ Peak lateral resistance for positive and negative loading direction for third cycle of loading sequence.
Emaks Peak lateral resistance.
$E_{S} \quad$ Elastic modulus of the steel.
$f_{c}^{\prime} \quad$ Compressive strength of concrete.
$f_{y} \quad$ Yield stress of the reinforcing bars.
$f_{u} \quad$ Tensile strength of reinforcing bars.
$\mathrm{F}_{i} \quad$ Lateral earthquake forces.
$h_{c}, b_{j} \quad$ The depth of the column section and the effective width of the joint, respectively.
$K_{b} \quad$ Initial lateral stiffness of the specimens.
$K_{E_{m a k s}} \quad$ Lateral stiffness corresponding to the peak resistance.
$K_{t, i} \quad$ Peak-to-peak stiffness.
$L \quad$ Clear height of the column.
$M_{z} \quad$ The moment on beam-joint interface induced by the beam shear.
$T_{c 1}, T_{c 2} \quad$ Resultant tensile forces at the column-joint interfaces of lower and upper columns, respectively.
$T_{b} \quad$ Resultant tensile force in beam at the beam-joint interface.
$V_{b}, V_{c} \quad$ Shear force in the beam at the beam-joint interface and shear force in the column at the column-joint interface, respectively.
$V_{j s} \quad$ Horizontal joint shear force.
$\beta_{i} \quad$ Relative energy dissipation ratios.
$\gamma_{x z} \quad$ Joint shear strain.
$\delta \quad$ Lateral displacement applied at column top.
$\Delta_{1, i}, \Delta_{2, i} \quad$ Drifts of $i^{\text {th }}$ loading sequence for positive and negative loading directions.
$\Delta_{E_{\text {maks }}} \quad$ Drift corresponding to the peak lateral resistance.
$\varepsilon_{x}, \varepsilon_{z}$
Strains in horizontal and vertical directions of the joint panel respectively. 


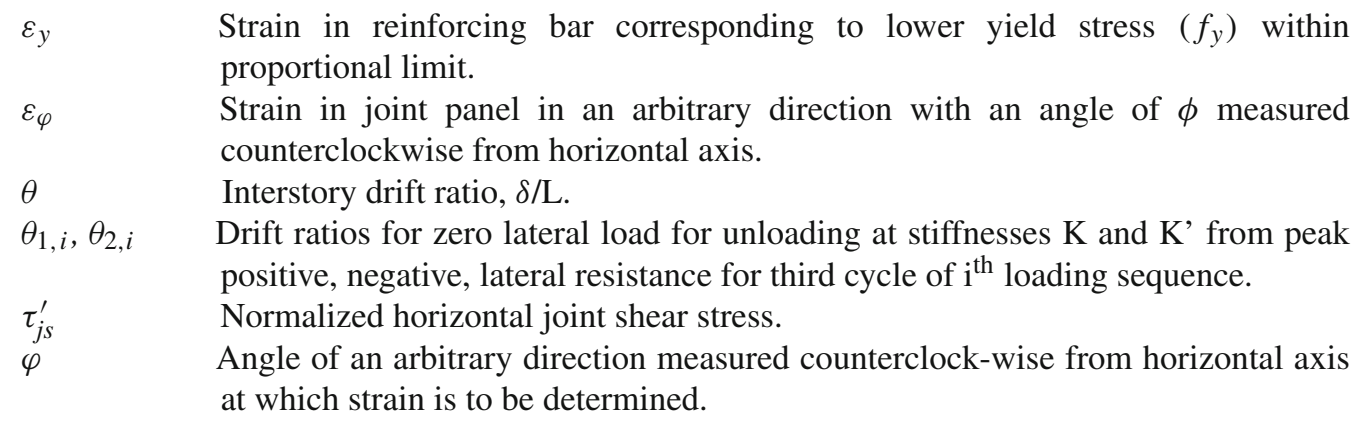

\section{References}

ACI Committee 3522002 Recommendations for design of beam-column connections in monolithic reinforced concrete structures (ACI 352R-02), MI: American Concrete Institute, Farmington Hills

ACI Committee 3742005 Acceptance criteria for moment frames based on structural testing and commentary, ACI 374.1-05, Detroit: American Concrete Institute, Farmington Hills, Michigan

Akguzel U and Pampanin S 2012 Assessment and design procedure for the seismic retrofit of reinforced concrete beam-column joints using FRP composite materials. J. Comp. Constr. 16(1): 21-34

Alcocer S M and Jirsa J O 1993 RC frame connections rehabilitated by jacketing. ACI Struct J. 90(4): 249-261

Beres A, EL-Borgi S, White R N and Gergely P 1992 Experimental results of repair and retrofitting beamcolumn joints test in lightly reinforced concrete frame building. Technical Report. Buffalo: NCEER-920025, SUNY

Binici B, Ozcebe G and Ozcelik R 2007 Analysis and design of FRP composites for seismic retrofit of infill walls in reinforced concrete frames. Composites: Part B. 38(5-6): 575-583

Canbay E, Ersoy U and Ozcebe G 2003 Contribution of reinforced concrete infills to seismic behavior of structural systems. ACI Struct. J. 100(5): 637-643

Dogan E and Krstulovic-Opara N 2003 Seismic retrofit with continuous slurry-infiltrated mat concrete jackets. ACI Struct. J. 100(6): 713-722

Engindeniz M 2008 Repair and strengthening of pre-1970 reinforced concrete corner beam-column joints using CFRP composites. PhD Thesis. Atlanta: Georgia Institute of Technology, USA

Engindeniz M, Lawrence F K and Zureick A 2005 Repair and strengthening of reinforced concrete beamcolumn joints: State of the art. ACI Struct. J. 102(3): 1-14

Erdik M 2001 Report on 1999 Kocaeli and Duzce (Turkey) earthquakes. Structural control for civil and infrastructure engineering, F Casciati and G Magonette (eds.) World Scientific, France

Gergely I, Pentelides C P and Reavely L D 2000 Shear strengthening of RCT-joints using CFRP composites. J. Comp. Constr. 4(3): 56-64

Ghobarah A and El-Amoury T 2005 Seismic rehabilitation of deficient exterior concrete frame joints. J. Comp. Constr. 9(5): 408-416

Ghobarah A, Aziz T S and Biddah A 1996 Seismic rehabilitation of reinforced concrete beam-column connections. Earthq. Spectra. 12(5): 761-780

Gokdemir H 2008 Seismic strengthening of beam-column joints. PhD Thesis. Eskisehir: Eskisehir Osmangazi University, Turkey. (in Turkish)

Hakuto S, Park R and Tanaka H 2000 Seismic load tests on interior and exterior beam-column joints with substandard reinforcing details. ACI Struct. J. 97(1): 11-25

Homrich J R and Naaman A E 1987 Stress-strain properties of SIFCON in compression. Fiber reinforced concrete properties and applications, ACI, SP-105. Detroit: American Concrete Institute, 244-251

Ilki A, Bedirhanoglu I and Kumbasar N 2011 Behavior of FRP-retrofitted joints built with plain bars and low-strength concrete. J. Comp. Constr. 15(4): 312-326 
McKenna 2011 OpenSees: A framework for earthquake engineering simulation. Computing in Science and Engineering. 13(4): 58-66. doi:10.1109/MCSE.2011.66

Misir I S 2011 Use of slurry infiltrated fiber concrete (SIFCON) in improving the seismic behavior of reinforced concrete structures. Ph.D Thesis. Izmir: Dokuz Eylul University, Turkey. (in Turkish)

Ozden S, Akguzel U and Ozturan T 2011 Seismic strengthening of infilled reinforced concrete frames with composite materials. ACI Struc. J. 108(5): 414-422

Pampanin S, Christopoulos C and Chen T-H 2006 Development and validation of a haunch metallic seismic retrofit solution for existing under-designed RC frame buildings. Earthquake and Structural Dynamics. 35: 1739-1766

Park R and Paulay T 1975 Reinforced concrete structures. New York: John Wiley

Parvin A, Altay S, Yalcin C and Kaya O 2010 CFRP rehabilitation of concrete frame joints with inadequate shear and anchorage details. J. Comp. Constr. 14(1): 72-82

Pimanmas A and Chaimahawan P 2010 Shear strength of beam column joint with enlarged joint area. Eng. Struct. 32(9): 2529-2545

Yazici H, Aydin S, Yigiter H, Yardimci M Y and Alptuna G 2010 Improvement on SIFCON performance by fiber orientation and high-volume mineral admixtures. J. Mater. Civil Eng. 22(11): 1093-1101

Wood B T 2000 Use of slurry infiltrated fiber concrete (SIFCON) in hinge regions for earthquake resistant structures. Ph.D. Thesis. Raleigh: North Carolina State Univ., N.C

Wu Y-F, Jiang J-F and Liu K 2010 Perforated SIFCON blocks-An extraordinarily ductile material ideal for use in compression yielding structural systems, Constr. Build. Mater. 24: 2454-2465 